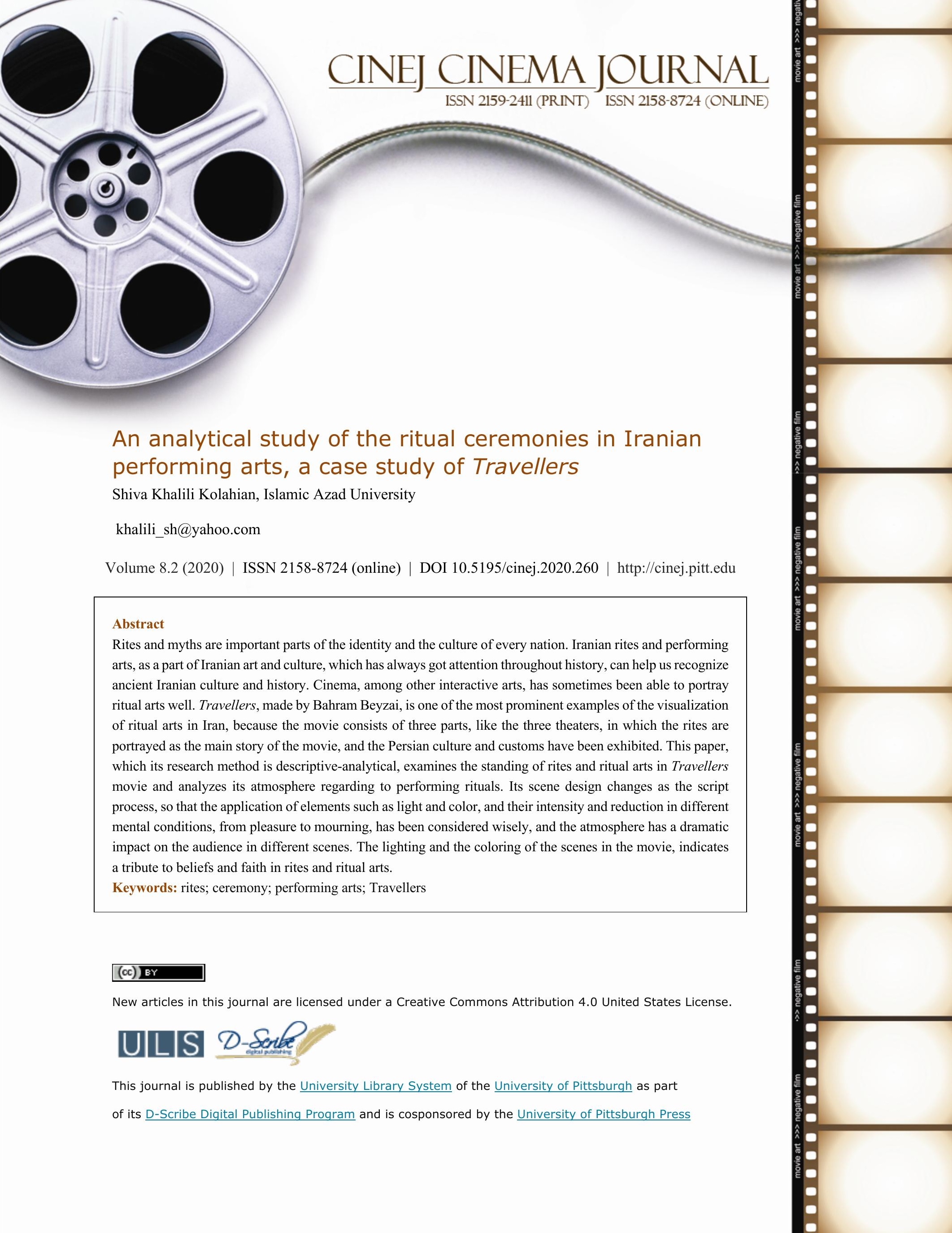




\section{An analytical study of the ritual ceremonies in Iranian performing arts, a case study of Travellers Shiva Khalili Kolahian}

\section{Introduction}

Religion is one of the things that has long existed in human societies and originated many cultural and social developments throughout history. The life of early human beings was completely associated with rites, which some of them are still visible in modern human societies, and they themselves can be a subject of study among sociologists and anthropologists. (Aghapoor, 2009: 12) The traditions and customs of a country can be displayed with the aid of performing arts. Cinema, as one of the most inclusive and universal means of communication between the performing arts and audiences, has been instrumental in expanding performing arts in recent decades. Cinemas can possibly offer the culture of a nation to the world. Hence, considering ritual arts in the movies, with respect to the role of cinema in the world, can play an important role in expressing the cultural and traditional rites of each country.

The screening of Bahram Beyzai’s films, puts him among those filmmakers who have been able to reconcile the audience with these traditions by expressing dramatically the traditional rites in the story. Beyzai's film Travellers tells the story of a traditional mirror that should be present at the wedding of the bride of the family. But an incident turns the wedding ceremony into mourning. The illustration of the details of the wedding ceremony and traditional beliefs on the scenes, is the goal that the filmmaker well achieved it. This paper, which is an attempt to analyze the ritual ceremonies in the Iranian performing arts, first provided a definition of rites and ritual arts in the cinema, then analyzed the status of the rites in the Travellers. 


\section{Research Methodology}

In this paper, descriptive-analytical method is used. In the descriptive method, first, a definition of rites and ritual arts is presented and then its functions will be examined. In the following, the role of religion and myth in Beyzai's cinema is discussed. By reviewing Bahram Beyzai's movies, it can be concluded that in most of his movies, including travellers, he has mentioned and paid attention to traditional rites and ritual arts. Then, a summary of the Travellers script is presented along with the analysis of the movie. In this research, what has been analyzed is the way that the rites and beliefs are portrayed, as can be seen in the movie. The study of scene design, lighting, the colors used in the movie, how the weddings and mourning held and their analysis, by reference to relevant library resources, and finally, their adaptation to the dialogues and the scenes of the movie are among the things which has been paid attention to in this paper.

\section{Research Background}

An article titled "The Transcendent of Mythical Time in Beyzai's Cinema" by Ibrahim Mohammadi and Maryam Afshar, surveys four of his cinematic productions, Ballad of Tara, Death of Yazdgerd, Maybe Some Other Time, and Travellers and examines the movies by mythological criteria and revealed that, in Beyzai's cinema narration, the time is close to the structure of its myths and, in other words it becomes incidental, endless, indeterminate, static, fragmental, holy and ritualistic and it is pointed out that within mythological insight, nothing, including time and place, has meaning of itself, but only every phenomenon in relation to the origin of divine becomes meaningful. The time comes to existence by the rites it is linked to. The Man reaches the mystical time through the path of any ritual action that can itself be the central event of the myth or rite, and passes from ordinary time continuity to sacred time through the rites without a risk. Each religious ceremony and any ritual time indicate the act of overcoming the continuity of the ordinary time 
and the revival of the mythological time that has been recited by the celebration and the ceremony. Hence, the sacred time is indefinitely reversible and repeatable (Eliadeh, 2009: 61). This periodic holding of religious and ritual ceremonies at certain, marked, and meaningful times, makes the time sacred. The ritual ceremonies revive and circulate mythical time at any moment (Shaygan, 1380: 140). According to Eliadeh, mythical time, is an eternal moment which in the life of ancient humans, its return was simultaneous with the happy days of celebrations and during holding rites. (Eliadeh, 1384: 8)

In another article titled "Revival of the rites with the suspension of time, place and personality in Bahram Beyzai's cinema" by Homeira Alizadeh and Maryam Afshar, semiotics and the quality of performing rites in Beyzai's cinema and the suspension of rites in three levels of time, place and personality, among the four aforementioned movies in the previous article, is discussed. Religion is the most significant sign in Bahram Beyzai's movies. By performing ancient rites, he tries to express his concepts and meanings, and, of course, makes a reminder of the forgotten Iranian identity. A sign is something that can be replaced by something else, and implies an equal subjective meaning, but there is no idea of the signs, without a code which acts as a framework and signs become meaningful through it. Therefore, to study rites as a sign, it is necessary to study the elements that are combined based on special rules and express meaning. Amir Hossein Nadai et al, studied "Spring, Summer, Autumn, Winter, and Spring" movie by the korean director Kim Ki-duk ${ }^{1}$, searching for function of ritual arts in the movie, and the result is that the ritual art in the movie atmosphere is sometimes decorative and sometimes commemorative of traditions and the past, and actually these arts were inspired by the eastern spirit, art, and thoughts of the filmmaker. 


\section{Rites}

In Moin Encyclopedic Dictionary and in Dehkhoda Dictionary, the word "آيين is expressed in many different meanings, which this can indicate the vast meaning of rite and its inclusion and coverage. Also, in the Britannica Encyclopedia, the word "rite" equals the Latin word "ritus", means religious ceremonies, and these meanings are shown in the following diagram. 


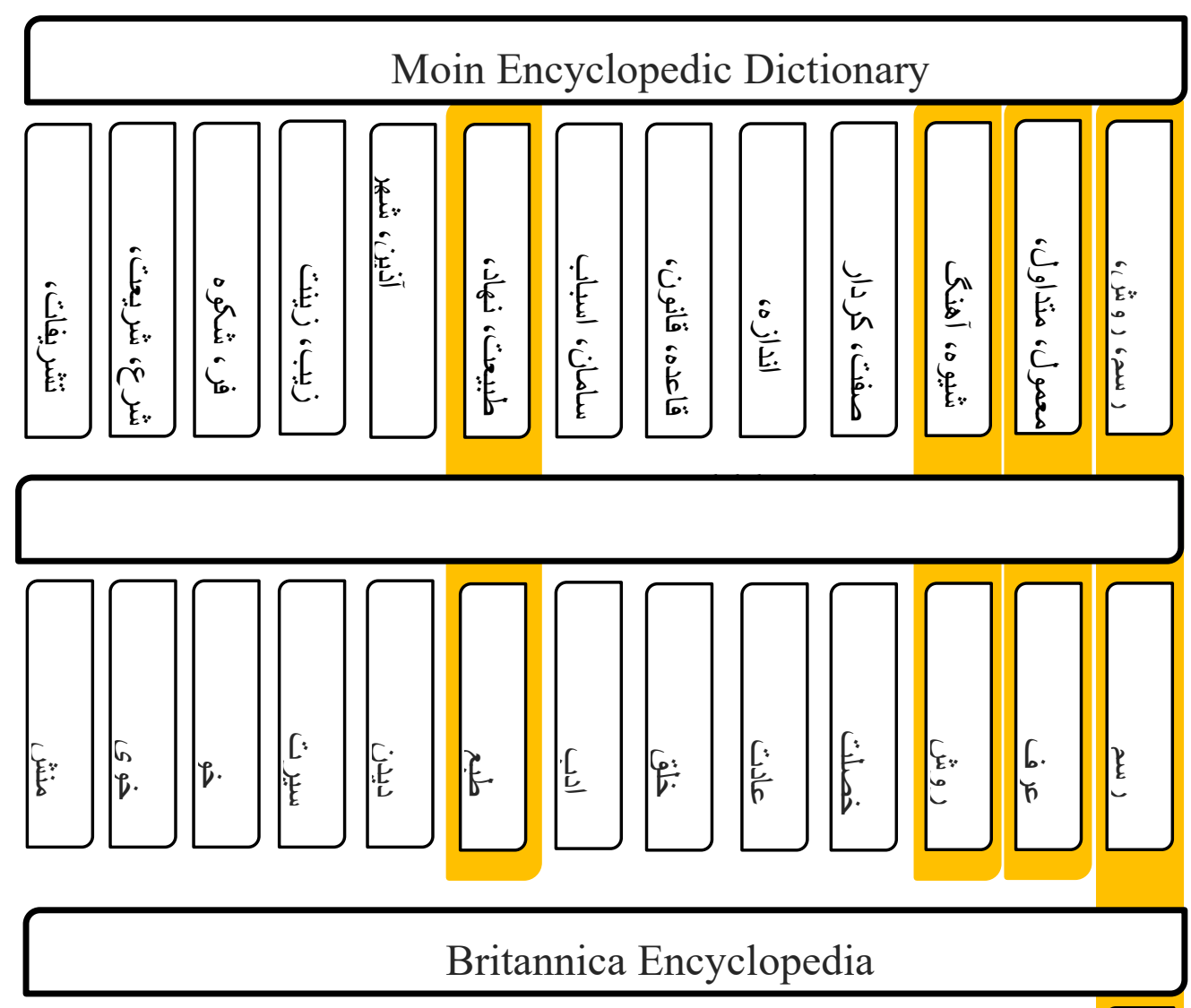

A prescribed form or manner governing the words or actions A ceremonial act or action done by a certain group of people or societv. 
The result of the synonyms and meanings of "rite", shows that "rite" is referred to a method or a set of methods that follow various functions and purposes in life.

Rites are a part of religion and creed, and basically considering the attitudes and beliefs of the early humans to supernatural forces, human life has been dealing with different rites from the beginning, and these rites have become more complete in terms of details and hierarchy and morphed into ritual ceremonies over time. But on the other hand, in determining the origins and the roots, the ritual has a special significance and has been carefully monitored by anthropologists.

In a general definition, a rite is a public, standard, and stereotype ceremony. But historically, sometimes it has a deep and maybe unbreakable connection to religious ceremonies, and occasionally it has a completely different meaning to rituals, customs and traditions. While non-ritual intellectual rationalism has been posed as the task of regulating western modern society, the rite is believed to have linked to primitive cultures, both objective and sensible knowledge and the mythologizing human being. (Eliadeh et al., 2009: 122). The rite has had various definitions since a long time ago. Some people like Durkheim ${ }^{2}$ believe it as religious ceremonies and indicate the path of the rites between sacred and unholy. Some people also assume rites as a remnant of culture and some other reckon it as a cultural element. This new analysis avoid the unrealistic distinction between religious rites and political rites, and transcend the duality of holy and unholy, traditional and modern, focusing on the connection between power and holiness. The same religion today calls on human beings to expand their limits, to make themselves as gods and heroes of mythology, to be placed among them, and to act like them. For this reason, myths and rites are linked together. The direct and indirect myth that leads to the ascension and elevation of man, is not independent itself and is dependent on the rites, because the narration or implementation of myth as the means of conceptualizing the holiness is one of the fundamental aspects of the rites. 
The myths, which are inseparable parts of the culture of nations, have had a special value among human beings, especially the early humans, because man always finds his aspirations and desires in mythology and attempts to preserve them. Although various nations and countries have held special celebrations and ceremonies to preserve their mythologies and rites hitherto, but today the cause and the origin of their actions has been forgotten. Nevertheless, rites and myths remain inseparable parts of the culture of all societies.

The researchers have categorized the rites into different categories:

1- Ancient celebrations and ceremonies, mythical and seasonal

2- Religious ceremonies

3- National, Patriotic and governmental celebrations

4. Family celebrations

5. Regional celebrations (Rooholamini, 2004: 15)

Human rituals is about the mysteries and crises of birth, puberty, marriage, treatment, death, war, predation, and seasonal cycles with periods of planting, harvest and their inactive days, and rains and droughts, disaster predictions and sudden natural events, and so many other issues. Human rituals make use of sacrifice, violence and tribute to express explicitly or implicitly the desire to succeed in living or dying. Combining music, dancing and theater, making harmonic sounds and performing group gestures, performing shows using smileys and showcases and fireworks, all create a deep sense of human dignity and satisfaction in audience or enthusiastic people. Also, the religion has benefits that can be explained as follows:

1- Religion is a form of knowledge. Because it tries to define man and his relationship with the world. 
2- Religion can be a method of teaching, because the primitive society is characterized by lack of written language, and the implementation of the rites is a means of transferring knowledge and traditions from one nation to the next generations.

3- Rites may be implemented to restrain future incidents. One of the main tasks of the rites is to achieve intended result, such as the success in the war, the proper raining, or the acquisition of supernatural power.

4- Rites are often used to honor supernatural forces, to success in predations or wars, and to praise history of a tribe, a hero or a totem.

5- Rites can be entertaining and delightful. Even the most serious ceremonies can be entertaining when they are displayed, either repeated as a formal standard, or performed by skilled performers. (Bracket, 1366: 32)

\section{The topicality of religion in tracing the origin of the show}

There are various theories about the origin of the show, the most significant one is the ritualism origin. First, the early humans did not have a correct perception of natural factors, but they would link those factors to supernatural and magical forces and seek to find a solution to get supported by those forces and also invented some procedures for this cause. Most of these procedures were dramatic gestures and actions which gradually tuned into rites and ritual ceremonies. The history of the show in Iran, like other kinds of arts, is thousands of years ago. In Iran, the origin of the show should be sought among celebrations, rituals, myths and poems. The show was first originated from the evolution of religious traditions and displays. The monotheistic religions in Iran, such as Zoroastrian or Islam, were less appealing to displayability than polytheistic religions, as in India and Greece. (Beyzai, 1344: 2) 
Therefore, in the most comprehensive origin theory of theater, it is believed that the theater has derived from rites and then evolved. Before the invention of the line and among the early societies, rites were a form of knowledge and a means for recording the events, sacred beliefs, customs, and history of the tribes. A ritual show would unify the viewers, who were also performers, in a creative and collective activity. The individual truth would unify the participants with their universal and cosmic truth and unleash the spiritual and ethereal power of the tribe or the congregation. Also, rites and hobbies have always been interwoven throughout history, and sometimes overlapped in terms of function.

The rites in oral era was a universal application and was considered to be the most important means of social communication and, fulfilled more or less the same tasks that nowadays the show is doing. Thus, the rites were able to provide elements that were fundamental for the future of the theater, such as the perform location of the performers, the performances, and the audience. As a result, rites created formats for human pseudo-theater performances. All performances, whether religious or non-religious, include formats. Formats adjust and indicate the time, mood, or subject changes or show that the implementation is about to begin or that the return to normal is near. Sometimes the templates are so common that they are being forgotten. Dimming lights, flaming candles, cheering and applauding at the end, and spraying perfume are of the factors that make connection between religious, aesthetic, and many intermediate forms.

On the subject in what stage of human evolution throughout history, the rites turned into theater, considering the fact that the content of the rites did not have a written form, it can be guessed that the rites, due to repetition and continuity, as very precise ceremonies in oral culture, has become accepted and refined, and as performing rituals became textual, the show was created. 
Since then, the show as an independent, creative, and regulated activity, has continued to live along with different human civilizations in various forms. (Aghapoor, 2009: 6)

What theorists of the theater say about the rites, is that it is the subject of anthropology. But at the same time, anthropology sometimes participates with other sciences such as semiotics, linguistics, and sociology in the study of the phenomenon of religion. During the past century, anthropologists have written a lot of articles about the relationship between rites and cultural organizations and thoughts, and despite the differences in their approaches, they all agree on one point, and that is, rites are important elements in all societies. They all admitted that the theater originated from primitive rituals. But some researchers still draw a clear line between rites and theater, while some other believe that the differences are so insignificant that most rites should be considered as part of the history of the theater. Performance everywhere has always been in relation to religion. This close and mutual relationship has sometimes been friendly and sometimes hostile. There is nothing in performance that intrinsically oppose or support religious affairs. Archaeological and anthropological evidence indicate the linkage between religion and performance, at least since the Paleolithic age. Evidence of ethics also confirms that rites and performances are quite similar among humans. The shows are repetitive, intensive, exciting and communicative. Coherent religious beliefs, pleasures and theories of aesthetics, manners and politics are some of the usages that humans have found for their rites.

\section{Synopsis}

Mahtab, the sister of Mahrokh, along with her husband and two young sons, travel with a ride from the north to Tehran to bring her family's hereditary mirror to Mahrokh's wedding. A villager woman gets in the car on the way. But they all die in a car accident with a tanker. The news comes to the family and the wedding turns into the mourning. Police reports do not reveal the hereditary 
mirror, although it shows the accident and the death of passengers. While the whole family has accepted the death of passengers, the grandma does not mourn, and she awaits for Mahtab to bring the bride's mirror. Against grandma's will, the mourning takes place, and the relatives of the dead, the tanker driver and his apprentice, officers and other people attend the ceremony. But meanwhile, Mahrokh appears distressed in a wedding white dress. Among the different reactions of the audience, suddenly Mahtab and other dead people come along with the hereditary mirror. The light reflection in the mirror, drowns the crowd in brightness. Mahtab brings the mirror to Mahrokh to hold the wedding.

\section{Analysis}

In the first scene, there's a mirror that lies on the floor by the sea and the sky light is reflexing on it. This mirror represents the tradition of a family; the Ma'arefi family that on all its girls and brides marriages, this mirror was present, and was always handed to the new bride; as the grandmother in a scene of the movie, askes her daughter in law Mastan: "Mastan, you have seen the mirror, right?! On your wedding. Moones can remember it that it was present in each of us weddings. We handed it to the new bride in the next wedding. After the last wedding it was lost. It was drifted to a junk shop by mistake. It took so long for Mahtab to find it. We agreed that she keeps it." (Beyzai, 1371:22) 


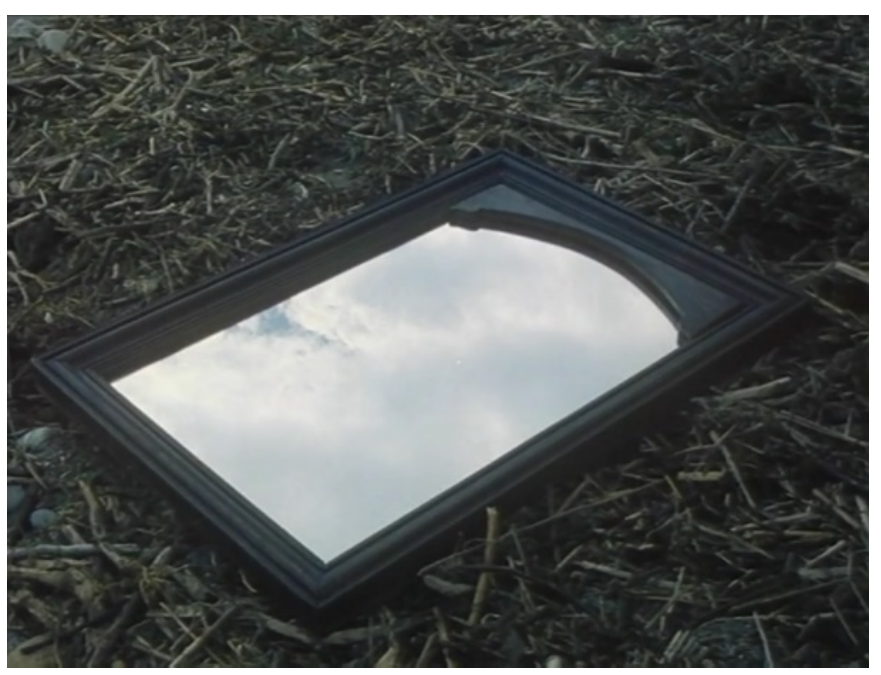

Figure 1. The mirror in the first scene.

The placement of mirror and candlesticks in the wedding table of the bride and groom is an ancient rite that has been existed since past and still exists in Iranian tradition and culture. But in this movie, the mirror transcends the symbolic role of the creator, and it becomes a symbol of the identity of a family. (Ghana'at, 1371: 74) As if without the mirror, they can't hold a wedding in Ma'arefi family. The mirror is a sign of everything good, brightness, purity, culture, hope, development, fertility, happiness, life, and so on. This particular mirror is a sign of continuity and fortune in the house of Ma'arefies. (Ghokasian, 1371: 167)

The Latin word "speculum" means the mirror, is the root of the word "speculation" means narrow thinking and reflection. Originally, this term meant observing the sky and moving stars with the aid of a mirror. The word "sidus" means the star, is the root of the word "consideration" means regard and observation, which from the point of view of etymology, means looking at the set of stars. These two nouns, "speculation" and "consideration", which mean reason and intellection, are rooted from the observation of stars in the mirror. From this, it turns out that the mirror, as a reflective surface, is the meaningful support of symbolism in the field of cognition and 
awareness. The mirror is the reflection of the truth, intimacy, inside heart and consciousness. (Knight, 1385: 323)

On this point of view, we can say about the "Travellers" movie, that the mirror is the symbol of reflection of a truth. As it can be seen in at the beginning scene of traveling passengers, Mahtab is about to bring the mirror to Tehran and receive it to Mahrokh, the younger sister. But before getting in the car, Mahtab says to the camera, "We're going to Tehran, for the wedding of my younger sister, we will not get to Tehran, and we're all going to die." (Beyzai, 1371: 8) While moving, the wind raises the laid cloth on the mirror, and the image of sky appears in the mirror. And then the accident scene occurs.

When the accident report hits the family, the grandmother does not believe, and in the scene where the police officer comes, she asks about the mirror. "Have you found a mirror too? They were carrying a mirror with themselves, if there's no mirror, then this must be another ride. She promised that the mirror will be delivered on time, she is on the way." (Beyzai 1371: 44)

But the grandmother who still believes they are on the way and that the mirror must be brought to hold the wedding, did not go to the burial, and says in a scene on the roof: "Come, come on Mahtab, if you don't come, her (Mahrokh's) life will will be wasted." (Beyzai, 1371: 48)

The head of Ma'arefi family is a woman called the grandmother, and the most important dialogues of the movie are also heard through her tongue. The grandmother represents the filmmaker's thinking, and she is the only one who doesn't give up believing in the return of Mahtab till the end. The focus on women in Beyzai's thinking is that even despite the common tradition that the wedding should be held at the groom's house, the wedding ceremony is holding in the house of Mahrokh. (Ghokasian, 1371: 94) 
Mahrokh complains about the delay of the travellers and says, "They will kill me until they come," and the grandmother replies: "Do not talk about death." Or her other dialogues in answer to Hekmat: "Bless you, please don't talk about death." Or elsewhere "do not talk about ruin; sweeten your mouth." She constantly forbids everyone from talking about death and unpleasant things, and until the end of the movie, she does not believe the death of the travellers. This indicates that she is a mother and the mother is the essence of birth (fertility) and myth of hope and life and she does not believe in death. Meanwhile, if her same sexes do not think so, it shows the strength of a mother who has just lost her daughter, and as a head of the family, she thinks, with all her hope, about her granddaughter's marriage. In all the images, her face is in the light and she does not lose hope. The divine intelligence reflected by the mirror is symbolically synonymous with the sun. From here on, the mirror is often assumed to be a solar symbol. But at the same time, it is a symbol of the lunar and the female, because the moon is just like a mirror reflecting the sun. (Knight, 2006: 325)

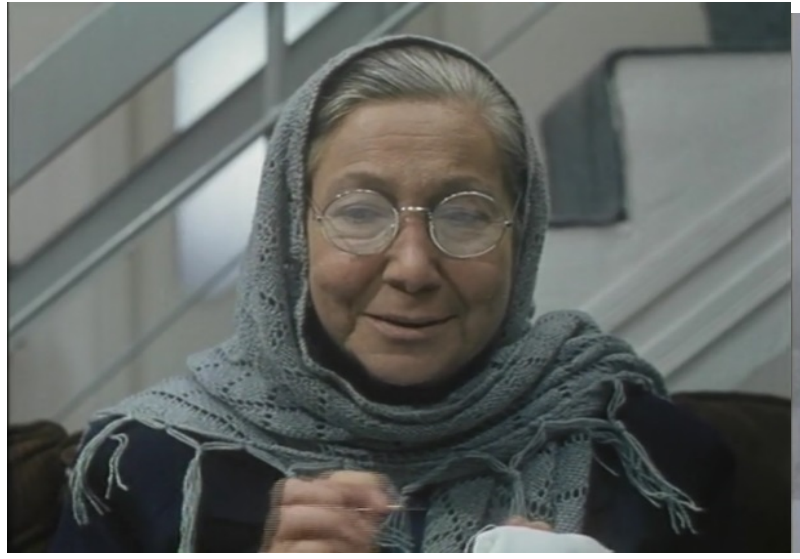

Figure 3. The grandmother.

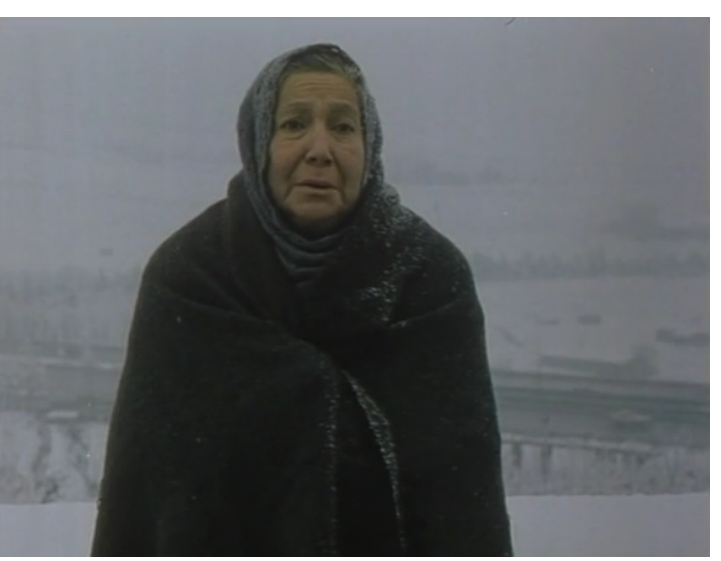

Figure 2. The roof scene.

In the mourning scene, the only person in the closed space and a dim light is the grandmother who isn't wearing black and she is still waiting for the travellers. The grandmother tells Mahrokh, "Everyone is dead, but not for me. I see them every day, my father was sitting there, 
my mother was sitting there and I was a kid. You were not there, does it mean that you were dead? Of course not" (Beyzai, 1371: 54)

The scene of the confrontation of the guests with the travellers is apparently based on two rites; the Ta'zie and the grieving ritual, which turns into a wedding ceremony, and the other ritual is the waiting for the dead to resurrect and the symbolic decline of the rites. (Farassati, 1395)

The faces are all in the light, and in the following, the Ma'arefi family members images, reflect within the mirror frame in pairs, and at the end, Raha hands a bunch of flowers to Mahrokh and the image of Mahrokh apears in the mirror. Meanwhile the grandmother says: "I told you that they were coming, she promised me, happy wedding my dear." (Beyzai, 1371: 67)

In the critique of this scene, Ghokasian believes that "the dead and the living are the mirrors of each other ... life and death ... wedding and grief ... especially for a nation who actually lives with its past culture and its dead" (Ghokasian, 1371: 167). At the final scene, the dead come and say happy wedding to the new generation. Here, in fact, the mirror brings happiness and fortune to Mahrokh which makes her bride and resumes the ceremony.

Figure 4.

Mahrokh in wedding

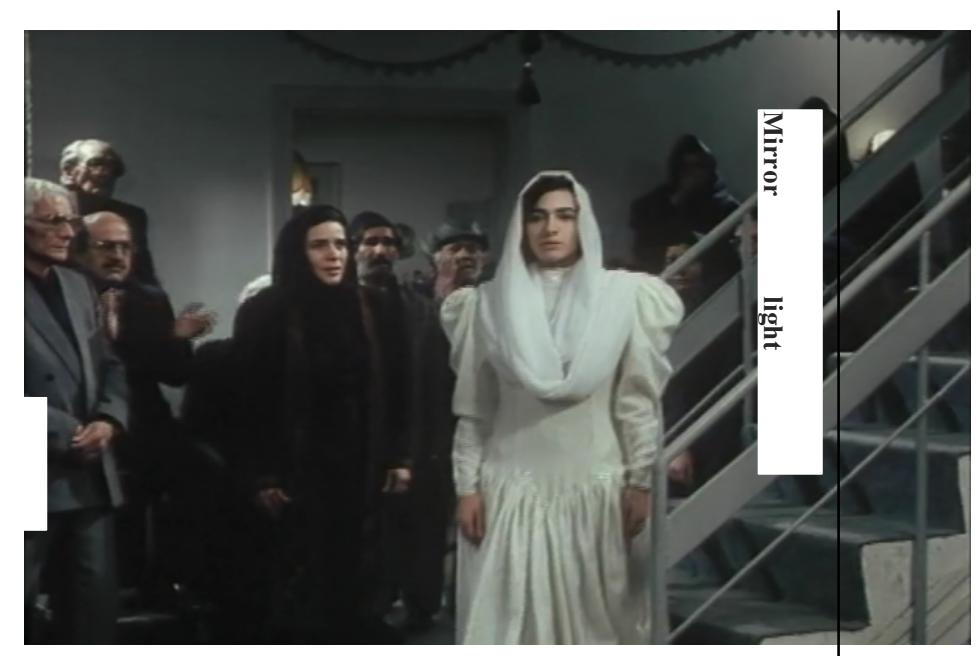


Figure 5.

Travellers' arrival

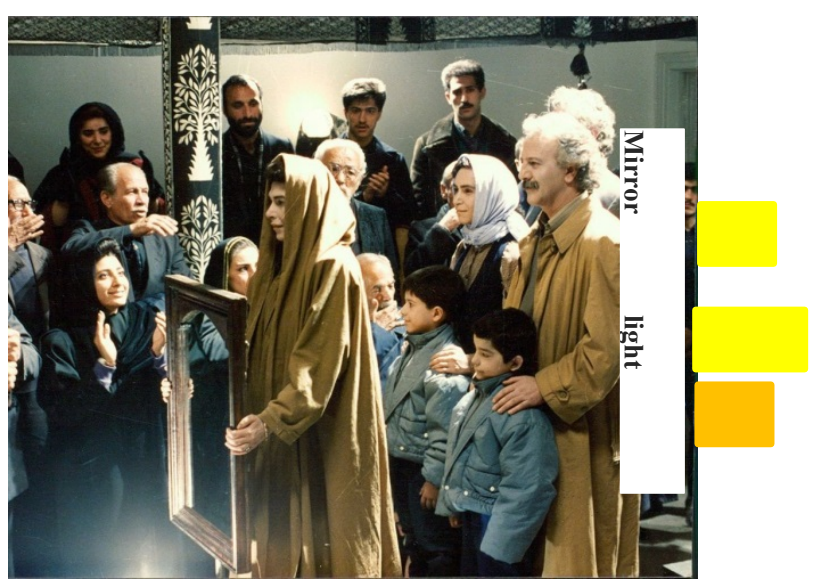

2

Figure 6. The

light on Mahrokh's face

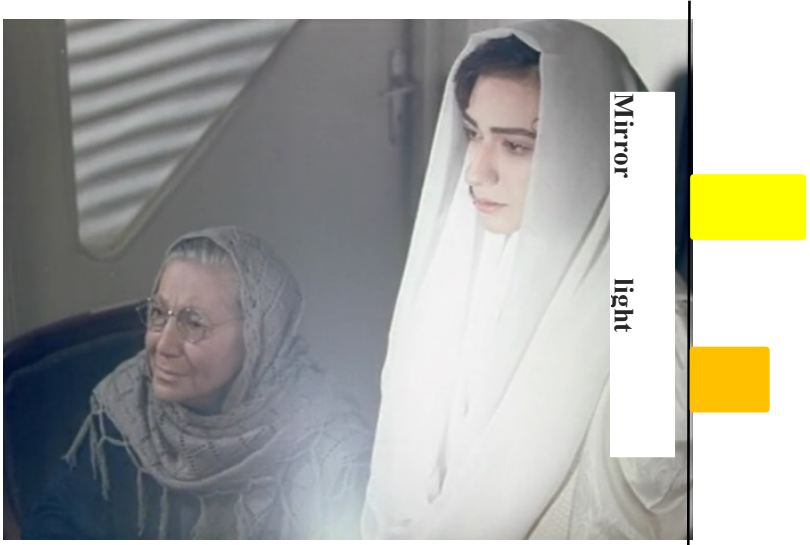

Figure 7. The

light on Grandmother's

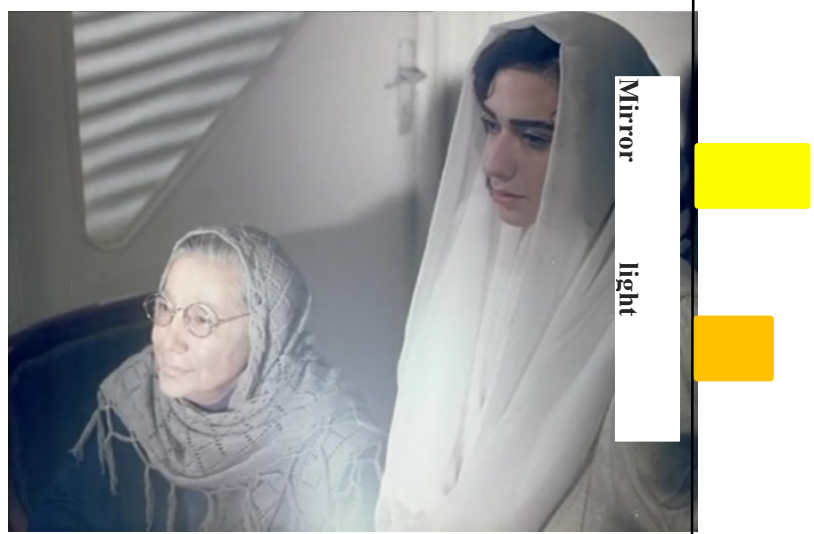


Figure 8.

Mahrokh coming

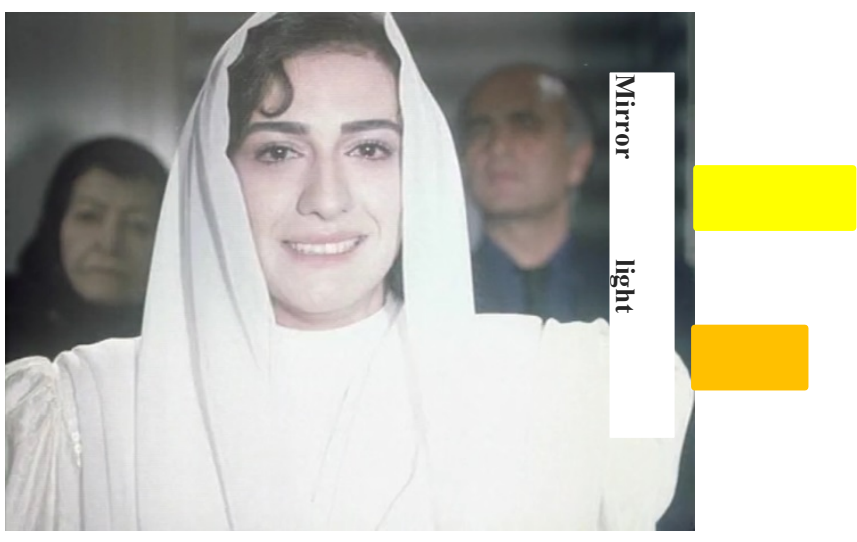

Figure

9.

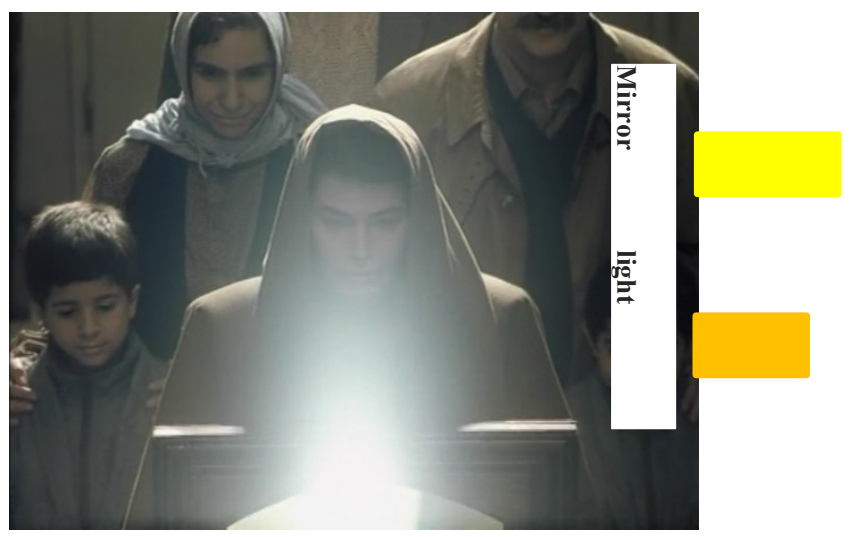

Mahtab in the lead with 
Figure 10.

Raha handing a bunch of

Figure 11. The two sisters'

Figure 12. The reflection of Mahrokh's face in the mirror, her
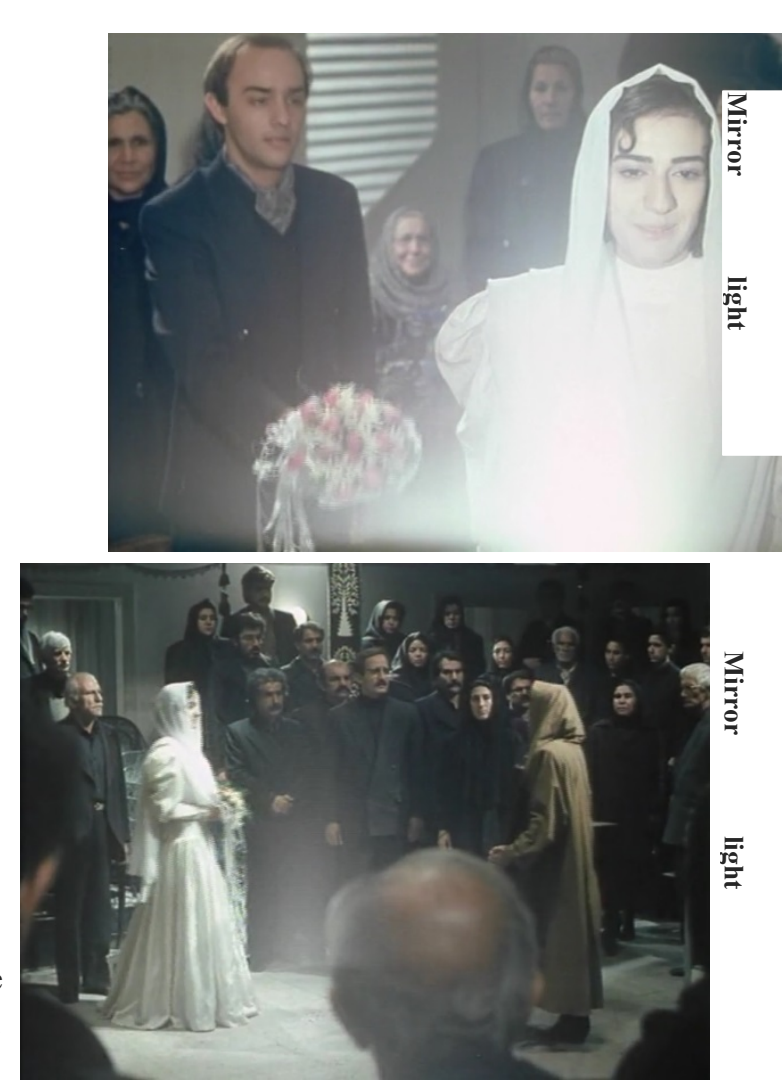

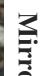
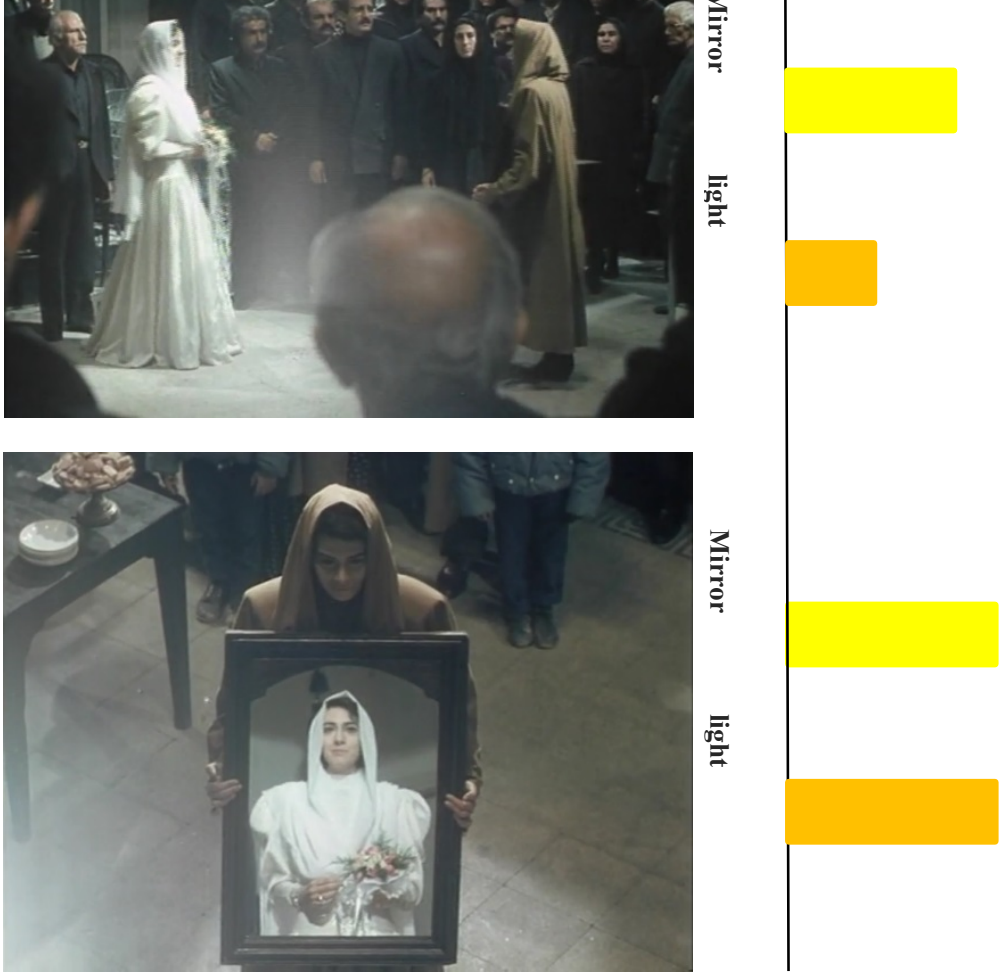


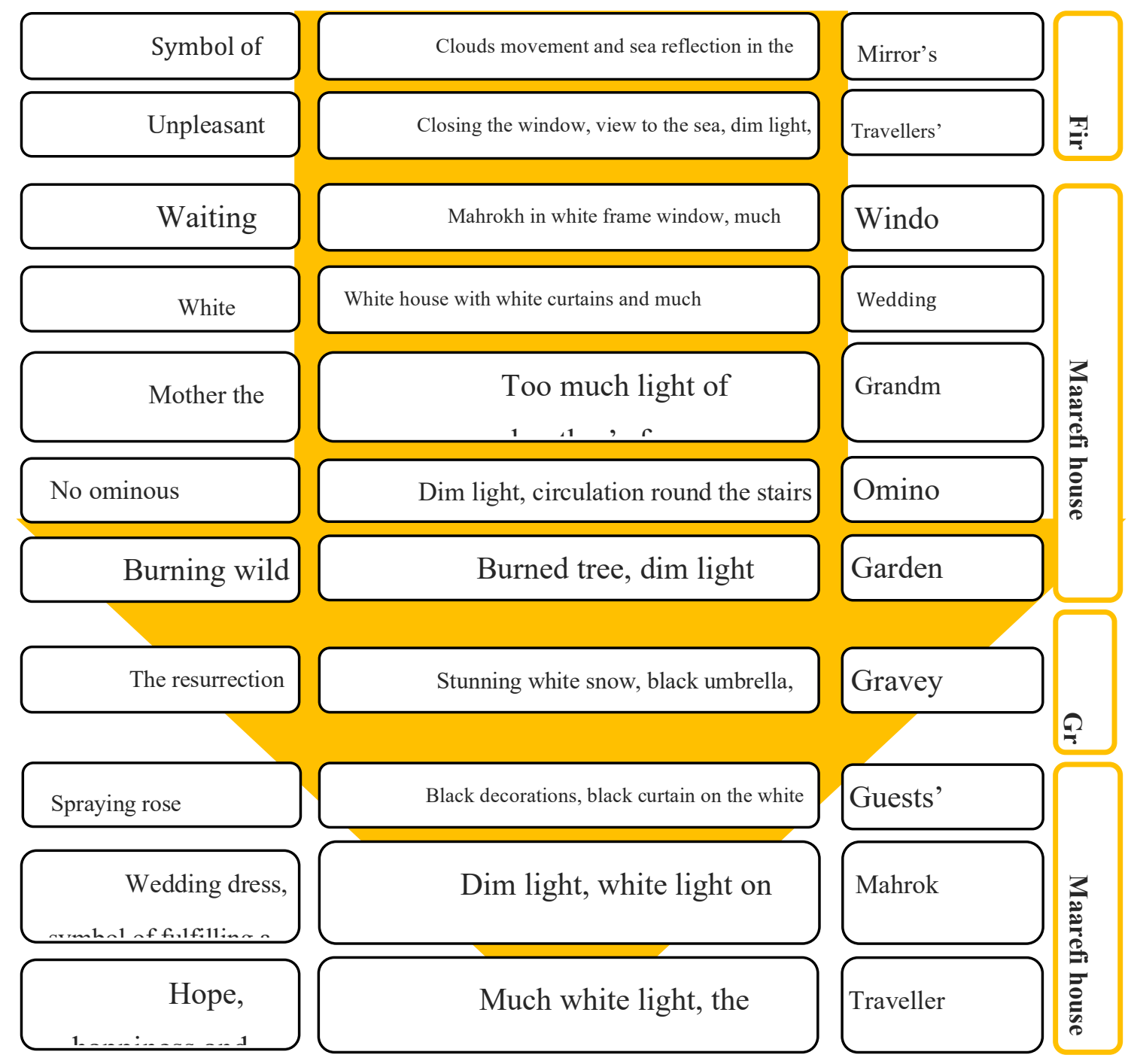

Diagram 2. Movie analysis 


\section{Description}

In Ma'arefi's house, everyone is trying to prepare the wedding ceremony and is waiting for the mirror. In the first scene, white doors and windows that are newly painted are portrayed. The household is lively trying to hold the ceremony. A large house with two floors, a bride's house, is Mahrokh Ma'arefi's. All together represent a house made of white color. White curtains are installed. The walls are white and the white covers are also given to Mahrokh by the grandmother to be covered on sofas. Wedding ceremony in all cultures and rituals is blessed and auspicious, and this matter in the Traveller's movie, is well felt by the furniture and the overall color of the house, which is white, and the splendor and the happiness of the house and the dominant bright light in the scene.

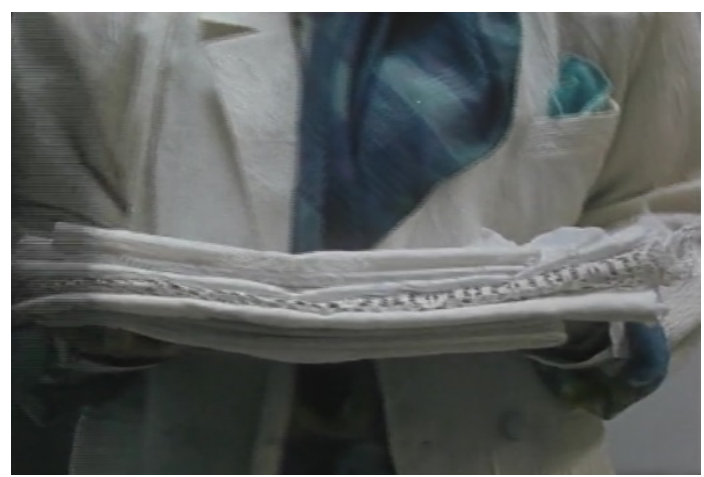

Figure 13. The white covers of sofa

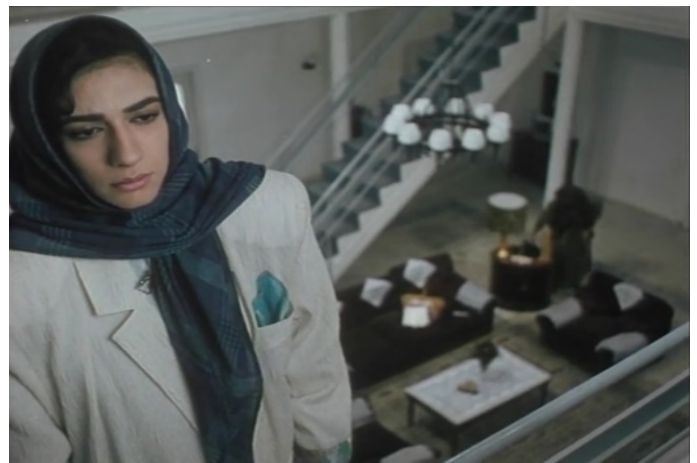

Figure 14. Ma'arefi's house overview

White is the symbol of purity and brightness, and expresses happiness, innocence, victory, glory and immortality. (Shahin, 1383: 3). But the first image of Mahrokh in the movie is within the window frame; a large white window similar to the old and noble windows which opens to a yard full of the autumn trees. Mahrokh smiles and takes a breath of fresh air. In several scenes, Mahrokh can be seen in the window frame. She is waiting for the wedding mirror and Mahtab's arrival, and with every car beep, she rushes to the window of her room. But every time it's someone else. In mysticism, the image of each person lies in his face and the image of his face is also lies 
in his eyes. By looking to a person's eyes, it is possible to somewhat understand his inherent characteristics. If we analogize a building to a man, its windows are like the his eyes, since it can be looked outside with, and if you look at that straight from the outside, you can find out the characteristics of the owner of the house. (Maleki, 1391: 136). With this description, the window can be said to be a metaphor of the Mahrokh's eyes as if waiting for the wedding mirror to begin the ceremony.

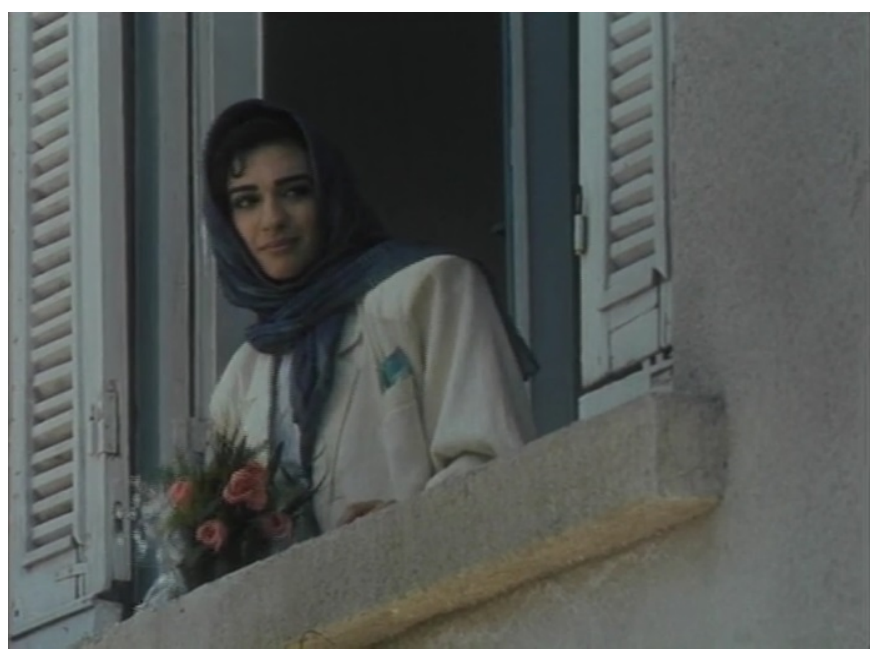

Figure 15. Mahrokh within the window frame

After hearing the travellers' accident news, everyone in Ma'arefi house accepts it and wears black clothes. They blacken the house and prepare for the funeral. Each member of the house shows his grief in his way, Mahrokh screams and breaks the crystalline fish tank, Hamdam smashes two white light bulbs together, Mastan breaks the clock, Mahrokh breaks the wall mirror into pieces. Moones tears the white covers. Kadivar chops the tree he had watered. Raha's mother brings down the white curtains, and the black curtains take their place and Mahtab's tree falls down. The atmosphere is dark and the light of the image, both inside the house and outside in the yard, is very dim. 


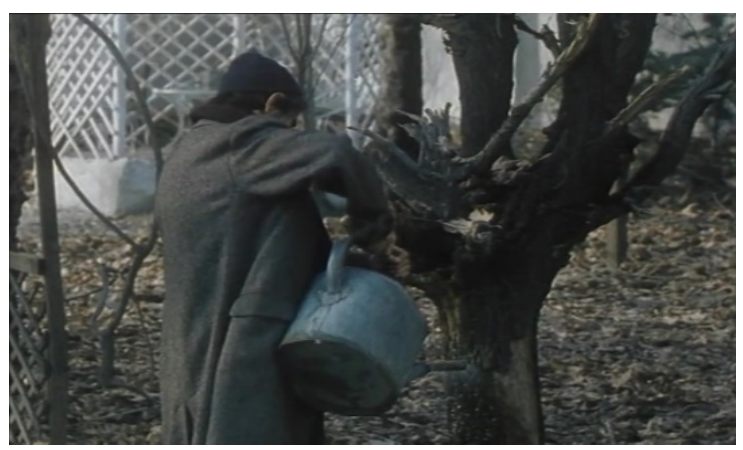

Figure 16. Watering Mahtab's tree

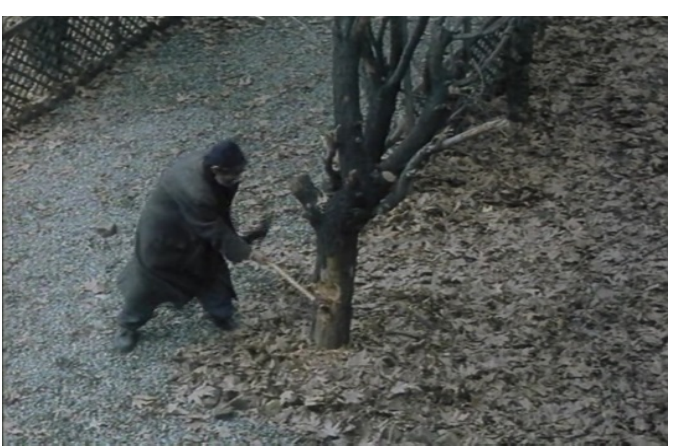

Figure 17. Chopping Mahtab's tree

At the funeral scene, first appears an image of the snow with a stunning light, although the brightness is low in the whole scene. Then there are several black umbrellas in the image, which is in contrast to the white snowy background. The funeral is going to be held at the house. The whole house is white; but it's covered with black. The light is again very dim and almost dark, and only the faces are a bit visible. Mastan and Hamdam spray rosewater and there are six empty seats in reminder of the dead, covered with black fishnet. In an interview with Bahram Beyzai, Zaven Ghokassian asks: "Does this tradition really exists in Iran?" and Beyzai responds: "Yes, it's a very old ritual, which still exists today in a more modern form. Manichaeists used to place a throne in Mani's memorial, which meant calling him, and also his absence, as well as the fact that he was spiritually present among them, and that he was superior to the assembly, and if he ever descended among the wakeful believers, he will sit in his place, and they also showed that they would never give his place to anyone else "(Ghokassian, 1371: 159)
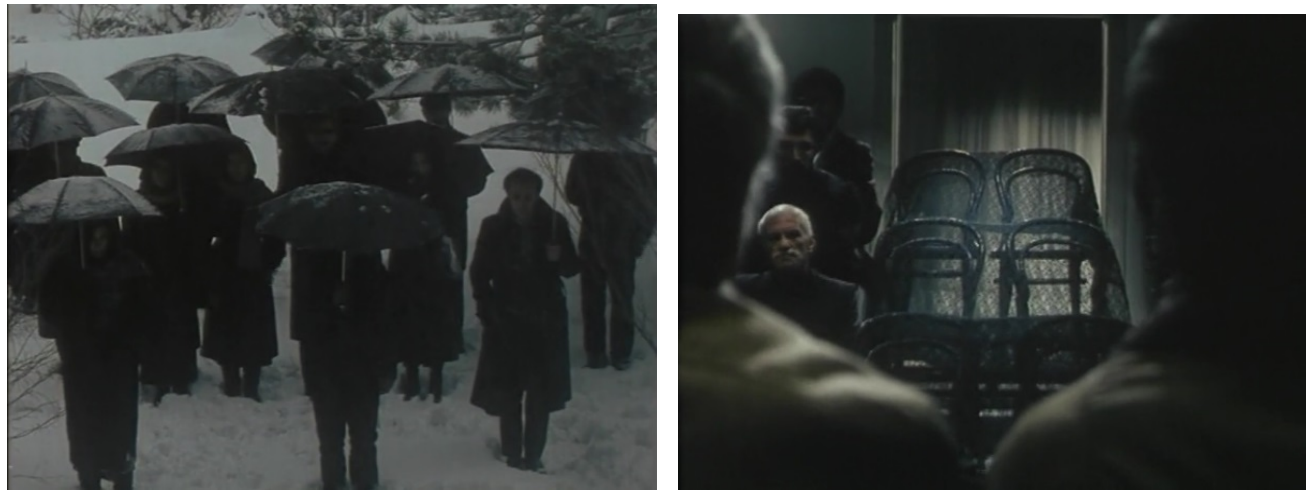

Figure 18. The funeral

Figure 19. The empty seats in reminder of dead 


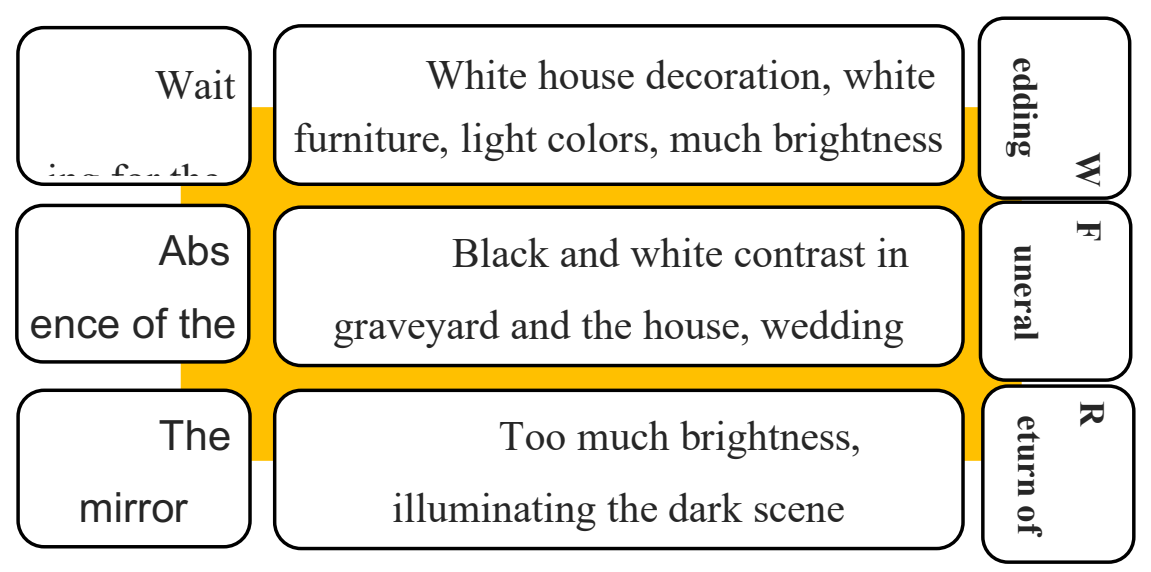

Diagram 3. Movie description

\section{Conclusion}

Since religion is a form of knowledge, it attempts to use a non-written language, so that besides communicating between man and the world around him, to be a means of transfer the knowledge and tradition of one nation to the next generations. Considering the various functional aspects of the rites, this transference can take place in entertainments and pleasures of performing ceremonies or even by acting on the stage of theater and cinema. Researchers have classified rites into a variety of categories, which one of them is holding family celebrations. Travellers is one of the movies in which these traditions are transferred by showing family traditions and ceremonies. The film consists of three sections; the first is the Mahrokh's wedding ceremony, the second is turning to a funeral, the third and final section is the arrival of the travellers with the mirror and the resuming the wedding ceremony. The main location of the movie is the Ma'arefi' house, which in fact two main sections of the movie, i.e. the second section and the final section of the movie, take place there. Therefore, what is being considered most, is the atmosphere of this house that the filmmaker utilized the wall colors and the furniture and also the lighting to define it. In fact, in 
introducing rituals such as weddings and funerals in the movie, which defines the space, is the use of appropriate light and color and considering these points. The main focus of the movie is an old mirror that contains the tradition of a family and without it, everything would be screwed up, what is dominant in the movie is the belief and respect for customs and traditions, and the bold mythical role of the grandmother as the head and the mother of the family who gets disappointed. In the final scene, having belief and faith in this, makes the filmmaker to direct the picture in a way that travellers are bringing the mirror from another world so that Mahrokh's life doesn't get destroyed.

\section{BIBLIOGRAPHY}

Aghapour, V. (2009). The study of the concept of ritual and ritual ritual from the perspective of

Grotovsky in the theater.tehran

Alizadeh, H.; Afshar, M., (1395). Re-creation of the religion by the suspension of time. place and personality in the cinema Bahram Beyzaee. Quarterly Journal of Dramatic Literature and Visual Arts. (3), Summer, 100-79.

Bracket, S. G. (1366). World Theater History, Translation by Houshang Azadevar, Volume I. First Edition. Tehran: Pearl Publishing.

Beyzai, B. (1371). Travellers Movie. Tehran: Roshangar Publishing House.

Beyzai, B. (1344). Show in Iran. First Edition. Tehran: Kavian Publishing House. 
Chevalier, J. and Gheerbrant, A. (2005). Symbol Culture. Translation by Soodabeh Fazaheli, Volume One A (Eomanis-Mirne). Second Edition. Tehran: Jayoun Publishing.

Eliade, M. et al. (1388). Myths and Rites (from ancient times to today). translation by Abolghasem

Esmailpour, Tehran: Myth Publishing.

Eliade, M. (2009). Holy and Unholy (The Nature of Religion). Translation by Behzad Saleki, Second Edition. Tehran: Scientific and Cultural Publishing.

Eliade, M. (1388). The myth of the eternal return. translated by Bahman Sarkarati, Tehran: Ghatra Publishing.

Ferasati, M. (2002). Missing at Labirent Times (Travellers by Bahram Beizai), Cinema Review, No. (35), pp.11-3.

Ghenaat, H. (1999). Travellers From the Viewpoint of Old Religious Beliefs. Reviewing and Introducing Beyzyani's Works. Collector Ghukkasyan Zavon. Tehran: AJ Publishing.

Ghukkasyan, Zavon. 1371. on Travellers. Tehran: Roshangar Publishing House.

Maleki, M. (1391). Seven windows towards mystical architecture. Tehran: Royan Pajouh Publication.

Mohammadi, I. and Afshar, M. (1393). A translated video of mythical time in Beyzaee Cinema. Literary Review. 25, 210-185. 
nedaee, A.; Alvandi, N.; Irani, s., (1394). Reviewing the function of Zen ritual arts in the spring, summer, autumn, winter and spring spring. Journal of Music Performing Arts, No., (11), Autumn and Winter, 63-51.

Rouholamini, M. (2004). Rites and Celebrations in Iran today. Tehran: Azad Publication.

Shahin, S. (2004). The study of the color symbol in the literary theater and in the religion of the nations. The Art of Fine Arts., (18), Summer, 99-108.

Shayegan, D.(1380). eternal idols and mental memory. Tehran: Amir Kabir.

\section{ENDNOTES}


${ }^{1}$ Kim Ki-Duk: South Korean director and filmmaker. The significant features of Kim Ki-Duk's cinema are interesting illustrations and the creation of stories without any dialogue or a few dialogues.

${ }^{2}$ David Emile Durkheim, the great sociologist from the nineteenth century to the beginning of the 20th century in France.

\section{Bahram Beizai' Travellers/Moseferan (1991) poster:}

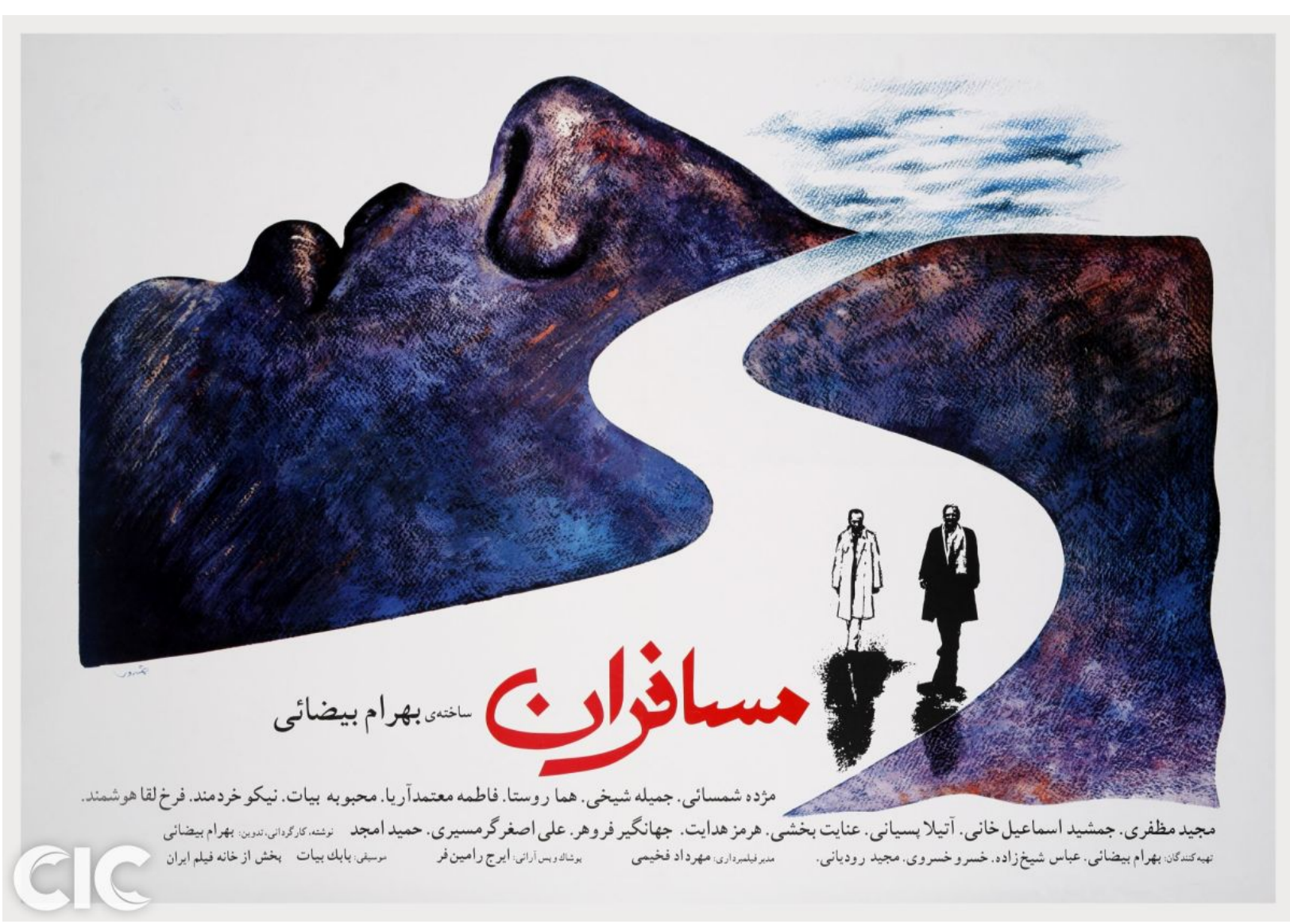


Still from The Travellers (1991)

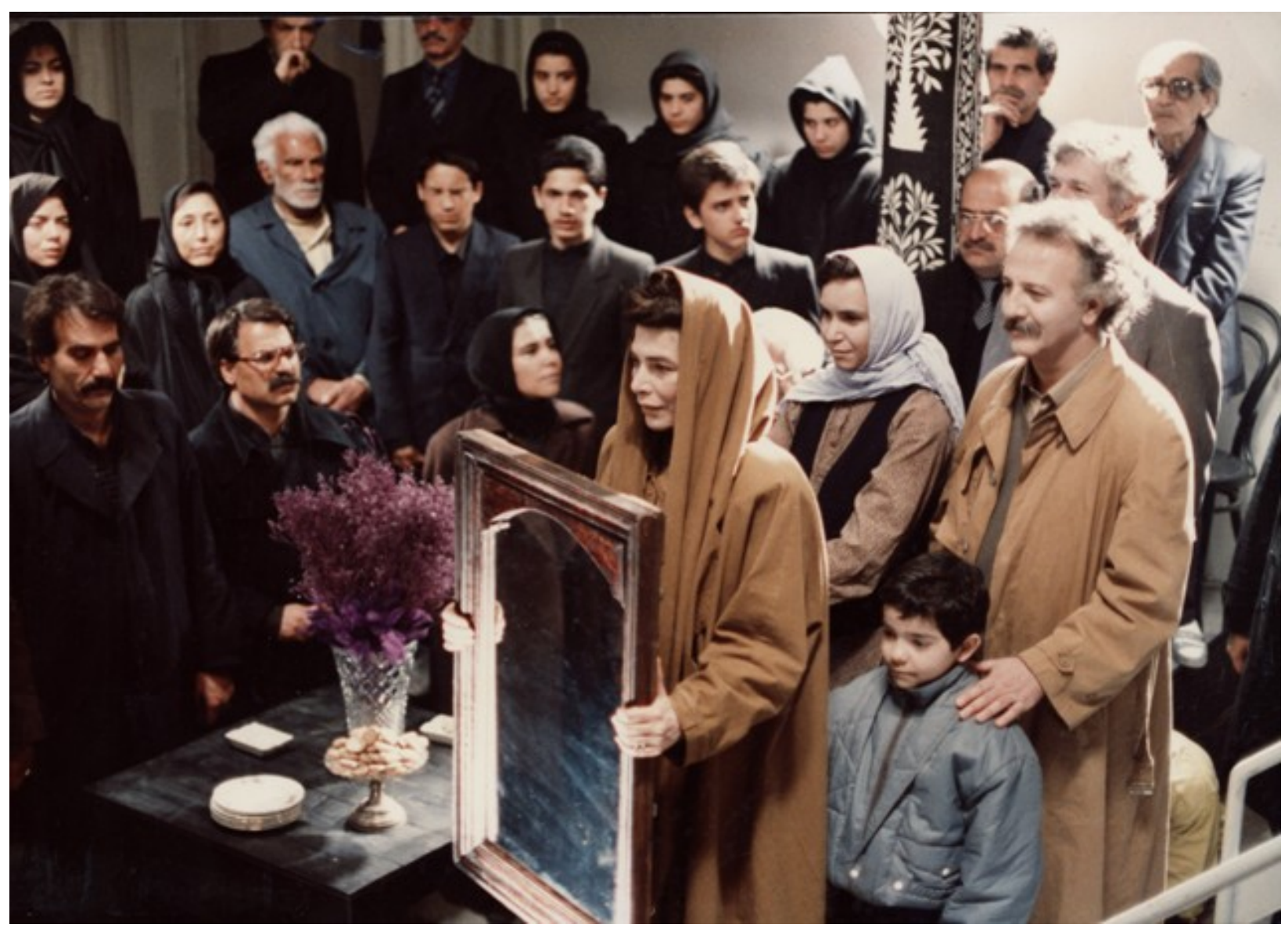


Bahram Bizai directing The Travellers

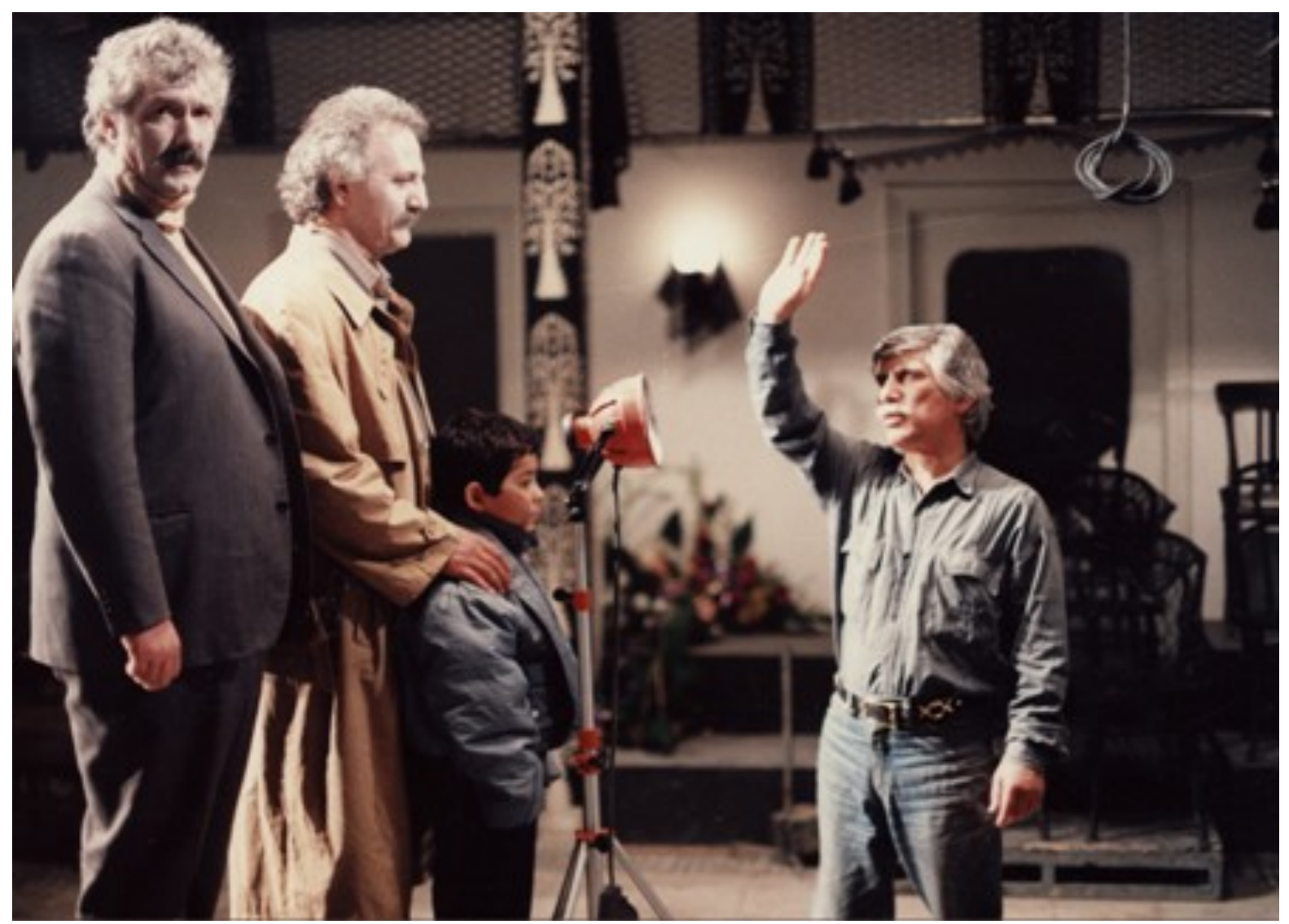

